\title{
KEEPING IT SIMPLE
}

I

HAVE BEEN WRITING technical research papers long enough for it to be second nature. A few years ago I wrote my first article for Oceanography, and I found it difficult. In retrospect, it should have been more difficult. I could have done a better job.

As editor, I have been dealing with colleagues (like me) experienced with writing technical papers, but not Oceanography articles. The objective for Oceanography is to publish succinct papers that are interesting and comprehensible to a range of ocean scientists. Here are some hints.

Content-Anything dealing with the field of oceanography is possibly revelantscience results, new technology, research programs, history of the field, thoughtful opinions. The key is that content be intrinsically interesting to a broad audience. Interdisciplinary science is a relatively easy sell. Disciplinary science should be framed in such a manner that understanding, appreciation, and interest for the article are easily reached by readers from other disciplines.

Style-We do not publish technical research papers, so natural instincts of scientific journey(wo)men must be stifled. For most papers, Methods and Results information should be minimized (instead, cite technical research papers). The emphasis should be placed on ideas typically found in Introduction, Background, and Discussion sections. Jargon and acronyms should be infrequent, and explained. The routine formats for article construction (e.g., units, abbreviations, references) are included on the mailing cover of every issue.

Length-We expect printed articles to be about seven pages in length. With figures and references, this translates into about 12 pages of DOUBLE-SPACED text. This length must be fully recognized at embryonic stages of article development. Twentyfive-page articles that are cut to 12 pages look like stumps, not well developed ideas. Authors, not reviewers or editors, should make the reductions. The key is to start with a limited number of points that can be properly developed in 12 pages.

Figures and Tables-Each of these should have a specific message that is easily recognized. Elaborate and busy presentations of data are not relevant to Oceanography. Captions are extremely important, and should tell the full story of the figure or table. Four or five figures/tables are the proper amount for an article. Labeling them as subfigures (e.g., Fig. 2a, 2b, 2c . . .) does not give license for inclusion of infinite figures. More than five is possible, but the final length limit for the article is still seven pages. And remember that color graphics are available for Oceanography articles.

The objective should be publication of an interesting and comprehensible article. Give a rough draft to a friend (even a nonscientist) for evaluation. If you get yawns or confused facial expressions, try some revisions. Get to your point quickly and forcefully, and above all else, keep it simple!

-Chuck Nittrouer

Letters are welcome regarding articles, the Quarterdeck editorial, or other matters relevant to Oceanography.

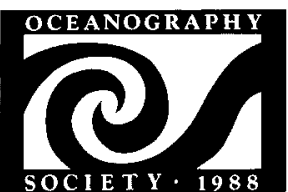

THE OCEANOGRAPHY SOCIETY

1124 Wivenhoe Way Virginia Beach, VA 23454 USA (804) 496-8958; fax: (804) 496-8960 omnet: OCEANOGRAPHY.SOCIETY

OFFICERS

Arnold L. Gordon, President Margaret Leinen, President-Elect D. James Baker, Past President Melbourne G. Briscoe, Secretary

David L. Evans, Treasurer

COUNSELORS Richard T. Barber Tommy D. Dickey Richard Jahnke Kevin D. Leaman Constance A. Sancetta W. Stanley Wilson Charles A. Nittrouer, ex officio

\section{EXECUTIVE DIRECTOR} Judi Rhodes

CORPORATE/INSTITUTIONAL SPONSORS Aanderaa Instruments, Inc., Woburn, MA, USA Chishitsu Chosa-Jo, Ibaraki, Japan GE Astro Space Division, Princeton, NJ, USA John G. Shedd Aquarium, Chicago, IL, USA

Monterey Bay Aquarium Research Institute, Pacific Grove, CA, USA

National Marine Fisheries Service, Silver Spring, MD, USA

Ober, Kaler, Grimes \& Shriver, Washington, DC, USA

RD Instruments, San Diego, CA, USA

Scripps Institution of Oceanography, La Jolla, CA, USA

Woods Hole Oceanographic Institution, Woods Hole, MA, USA

\section{Oceanography}

EDITOR

Charles A. Nittrouer Marine Sciences Research Center State University of New York Stony Brook, New York 11794 USA (516) 632-8651; C.NITTROUER Telefax: (516) 632-8820

ASSOCIATE EDITORS James W. Ammerman Department of Oceanography Texas A\&M University College Station, TX 77843 USA (409) 845-5105; J.AMMERMAN

Gregory J. Brunskill Australian Institute of Marine Science PMB No. 3, Townsville, M.C Queensland 4810, Australia (77)789211; G.BRUNSKILL

Ellen R.M. Druffel Woods Hole Oceanographic Institution Woods Hole, MA 02543 USA (508) 257-2000; E.DRUFFEL Donald B. Olson RSMAS

University of Miami Miami, FL 33149 USA (305) $361-4074$; D.OLSON.RSMAS 